\title{
Results of R.F. Noise Coupling Tests Done in Building 141
}

\author{
R. A. Anderson
}

December 1, 1999

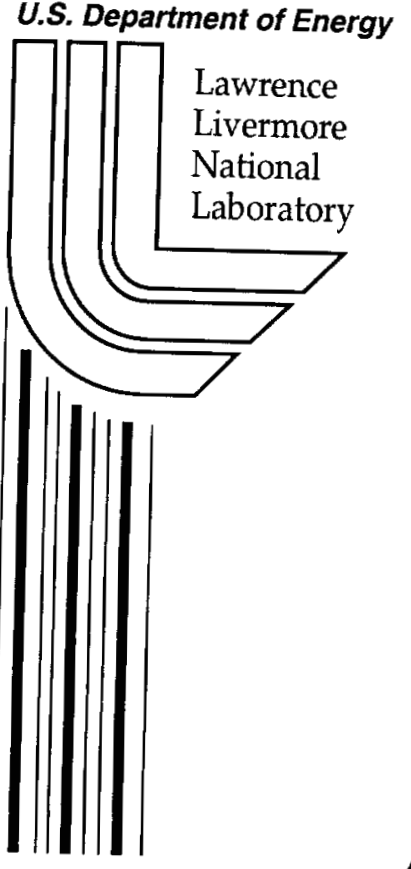




\section{DISCLAIMER}

This document was prepared as an account of work sponsored by an agency of the United States Government. Neither the United States Government nor the University of California nor any of their employees, makes any warranty, express or implied, or assumes any legal liability or responsibility for the accuracy, completeness, or usefulness of any information, apparatus, product, or process disclosed, or represents that its use would not infringe privately owned rights. Reference herein to any specific commercial product, process, or service by trade name, trademark, manufacturer, or otherwise, does not necessarily constitute or imply its endorsement, recommendation, or favoring by the United States Government or the University of California. The views and opinions of authors expressed herein do not necessarily state or reflect those of the United States Government or the University of California, and shall not be used for advertising or product endorsement purposes.

This work was performed under the auspices of the U. S. Department of Energy by the University of California, Lawrence Livermore National Laboratory under Contract No. W-7405-Eng-48.

This report has been reproduced directly from the best available copy.

Available electronically at http://www.doc.gov/bridge

Available for a processing fee to U.S. Department of Energy And its contractors in paper from

U.S. Department of Energy

Office of Scientific and Technical Information

P.O. Box 62

Oak Ridge, TN 37831-0062

Telephone: (865) 576-8401

Facsimile: (865) 576-5728

E-mail: reports@adonis.osti.gov

Available for the sale to the public from

U.S. Department of Commerce

National Technical Information Service

5285 Port Royal Road

Springfield, VA 22161

Telephone: (800) 553-6847

Facsimile: (703) 605-6900

E-mail: orders@ntis.fedworld.gov

Online ordering: http://www.ntis.gov/ordering.htm

\section{OR}

Lawrence Livermore National Laboratory

Technical Information Department's Digital Library

http://www.llnl.gov/tid/Library.html 


\section{Results of R.F. Noise Coupling Tests Done in Building 141}

Robert A. Anderson

December 1, 1999

Summary

As part of the lightning protection plan at the Pantex plant, coupling measurements were made by LLNL to determine the transfer functions of the work areas (cell or bay). From these measured transfer functions the susceptibility of the cell to a lightning strike can be determined, and the appropriate mitigating measures put into effect. The transfer functions are determined by injecting a current on the outside of the cell and measuring the electric field inside. The ratio of electric field to the injected current over a broad frequency range is the transfer function.

During one of our tests a comparison of LLNL and SNLA instrumentation was done. The major difference in the systems was that the SNLA system used batteries for power and a fiber optic link to decouple the antenna from the receiver. LLNL used $\mathrm{AC}$ power and a cable for the antenna connection. The comparison showed a discrepancy between LLNL and SNLA results. The source of this error was unwanted signal (noise) coupling into the local AC power source from the injected current. Since this source was used to power the equipment, the noise was fed directly to the electric field measuring antenna, causing errors in the measurement.

The main source of error was confirmed with a series of lab tests done at LLNL Building 141, using combinations of AC power, battery power, and a fiberoptic link. A noise model was hypothesized and the measured transfer functions were analyzed with the noise model in mind to show how the errors were introduced into the data. Measurements were made to show the decoupling effects of using ferrite cores on the instrumentation power cords. The necessary changes to the LLNL instrumentation was then made to avoid these errors.

\section{Discussion}

Figure 1 shows schematically the lab setup in B-141. Some of the RF coupling paths are shown from which a simple noise coupling model can be inferred.

The system operates by injecting a current into a water pipe with a clamp-on current probe. The pipe is located in the southeast corner of the bay and is connected to the building ground directly outside the wall. The other end of the pipe connects to the building structure via pipe clamps to the metal building frame. The transmitter current (I) will flow in the building structure and return through a myriad of $\mathrm{RF}$ paths (i) to the building ground and water pipe. Included in these paths are the AC power ground wire from the wall receptacle to the building ground. These currents will produce an electric field that can be measured at a location in the bay far away from the source, to avoid direct coupling of the transmitter to the receiver. Computers synchronize the source and receiver frequencies to collect data over a broad frequency range. From this data the transfer functions were calculated. To measure the currents a calibrated clamp-on current probe is placed around the current carrying conductor and the output fed to a spectrum analyzer to record the probe voltage. The probe factor is used to convert the probe volts to measured current.

The receiver consists of a broadband monocone (TCOM) antenna driving a high input impedance amplifier. The antenna is placed on the floor to utilize the floor construction rebar as the ground plane. The antenna produces a voltage proportional to the electric field from the antenna elements to the underlying ground plane. This is connected to a spectrum analyzer to record the antenna voltage. The antenna factor is used to convert the voltage to electric field.

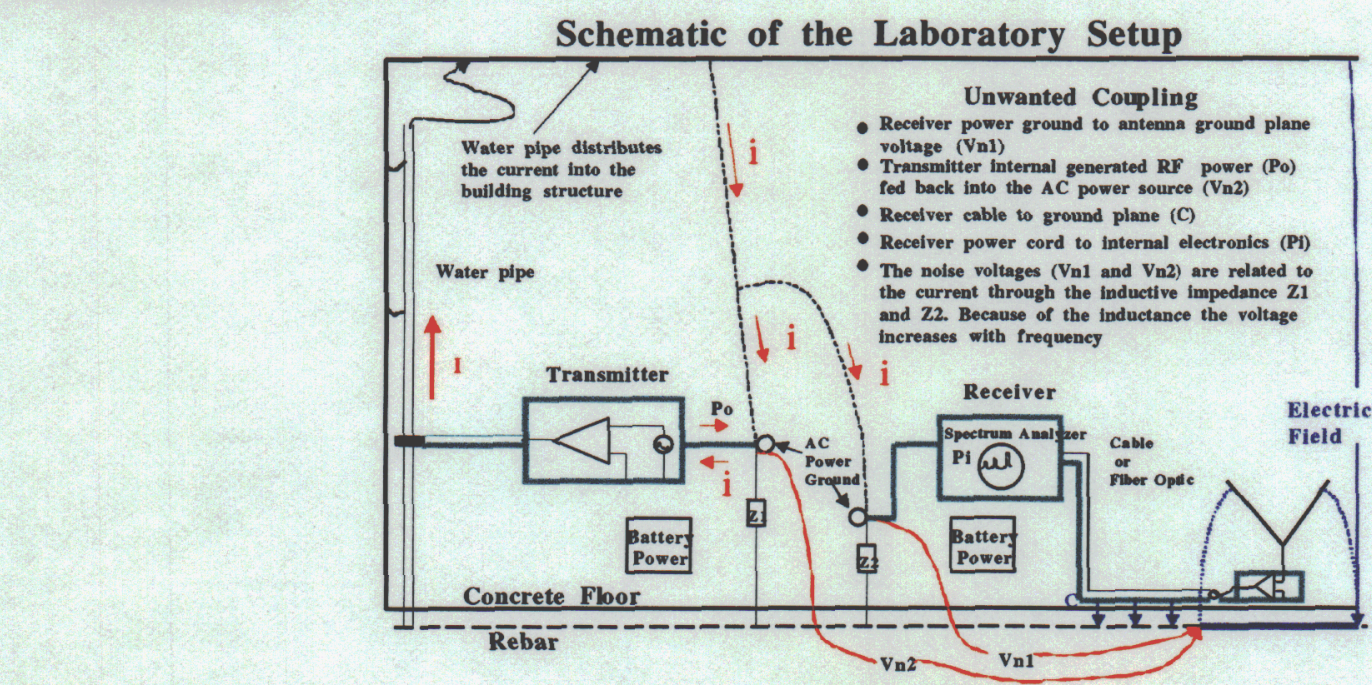

Figure 1. Laboratory set up. 
For proper operation (no unwanted coupling) the measurement system ground reference should be that region of the ground plane directly under the antenna.

From Figure 1, many sources of unwanted coupling can be identified. The data will show that the main source of unwanted coupling is that from the receiver AC power ground. It can be described as follows: from Figure 1, some of the transmitter current (i) returns to ground on the $\mathrm{AC}$ power ground wire. A voltage is developed from the ground connection in the AC wall receptacle that supplies power to the receiver, to the antenna ground plane (Vn1). This voltage is developed because of the return current flowing through the inductive impedance $\left(\mathrm{Z}_{2}\right)$ of the ground wire from the wall receptacle to the building ground. There is a relatively low impedance path from the receptacle ground connection to the antenna. The path consists of the receiver power cord ground wire, the receiver chassis, and the $20 \mathrm{~ns}$ cable shield. 1 and 2.

This is depicted by the heavy green line in Figures Unwanted Signal Coupling

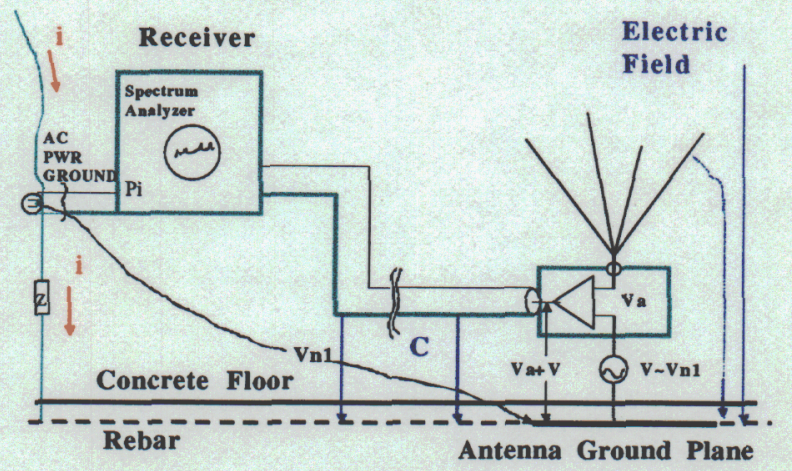

Figure 2. Vn1 in series with the voltage developed by the antenna from the electric field.

If this impedance is neglected, then the unwanted noise voltage $\mathrm{Vn} 1$ is effectively in series with the voltage developed by the antenna from the electric field as shown in Figure 2 and labeled V. More generally, V will be approximately equal to $\mathrm{Vn} 1$ as indicated. Clearly, the voltage at the output of the receiver will be the vector sum of the antenna voltage and the noise voltage (dependent on magnitude and phase). At this point, it should also be clear that the receiver ground should be isolated from the antenna, by using battery power, fiberoptic link or both. Since the ground wire impedance is inductive, Vn1 should increase with frequency, as will be seen in the results.

The other unwanted noise sources that were investigated are: 1) direct coupling of the unwanted signal $\left(P_{i}\right)$ from the receiver power cord into its electronics. This was found to be negligible. 2) coupling from the antenna cable to the ground plane (C) and indicated on Figures 1 and 2. This was found to be small. 3) coupling from the transmitter to the AC power ground $\left(V_{n} 2\right)$. As shown in Figure 1, there are currents flowing in both directions on the transmitter power cord. The current flowing outward is that generated internally and fed back into the $\mathrm{AC}$ power receptacle. Some of this current combines with the other return currents which produce the unwanted noise Vn1. This is the reason that isolating the transmitter from the AC power is desirable. However the data will show that this produces a small effect. The current flowing in to the transmitter from the power receptacle could capacitively couple an unwanted signal from the current drive transformer to the water pipe. This is a negligible effect. Reproducibility of the measurements and signal to noise ratios were also taken into account.

\section{Analysis}

The analysis begins by answering the basic questions of signal to noise ratio of the measurements and the reproducibility. Figure 3 shows the signal to noise ratio measurement for various receiver configurations. The transmitter was on, but the current injector probe was disconnected. For all configurations the signal (TCOM) to noise ratio is greater than $20 \mathrm{~dB}$ and its effect can be ignored in the data manipulation.

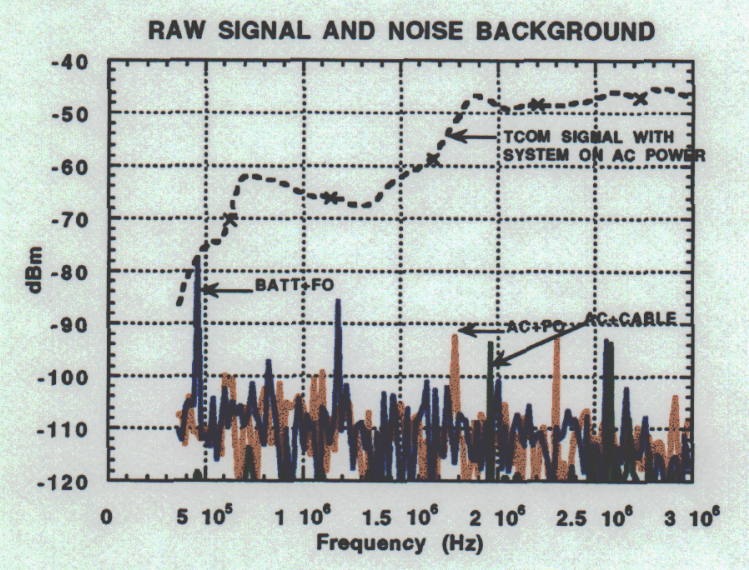

Figure 3. Signal to noise ratio

REPRODUCABILITY-RECORDS TAKEN ON DIFFERENT DAYS
SOURCE VARIABILITY NOT TAKEN INTO ACCOUNT

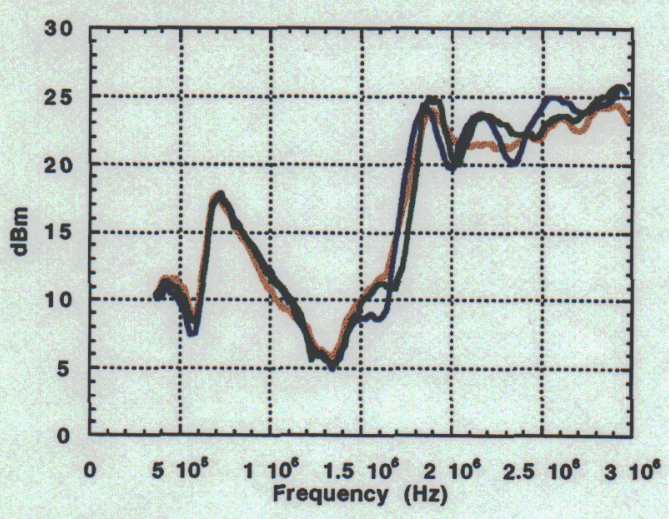

Figure 4. Reproducibility Data 
Figure 4 shows the reproducibility data. The electric field was measured on different days with the same instrument configuration. The data shows consistency to within $3 \mathrm{~dB}$. This is a small enough variation so that interpretation of the transfer function data is not affected.

The next step is to show that the coupling from other sources is small. Figure 5 shows that the coupling from the antenna cable to the ground plane relative to that from the antenna is small. When the system is operated from batteries the coupling is not measurable. When operated from the $\mathrm{AC}$ power the coupling begins to show above $2.5 \mathrm{Mhz}$, but is very much less than the antenna signal (TCOM), and can also be ignored.

Another source of coupling is that from the receiver AC power cord directly into its internal electronics.

\section{RAW TCOM SIGNAL AND CABLE TERMINATED IN 50 OHMS} AC AND BATTERY POWER

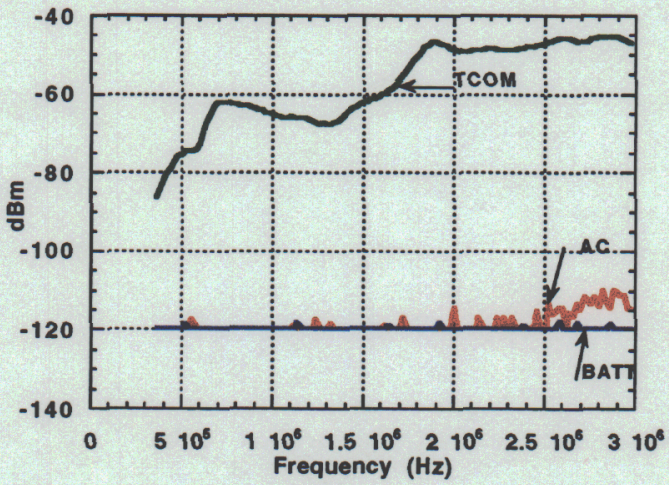

Figure 5. Coupling from antenna cable to ground plane.

The curve marked AC on Figure 6 is the ratio of current on the power cord to the drive current. This shows that the unwanted current on the power cord is a function of frequency that increases above $1.5 \mathrm{MHz}$. This current could generate magnetic fields that will couple to the internal electronics. Figure 7 shows that direct coupling of that current into the analyzer electronics is below the noise limit of the instrument. It was measured by terminating input of the analyzer in $50 \mathrm{ohms}$, and using the AC power source. Figure 6 also shows that by using battery power for the receiver the unwanted current on the power cord is dramatically reduced. Since the current on the power ground is related to the unwanted noise voltage, as described earlier, running the equipment on batteries would greatly reduce the unwanted noise at the antenna output.

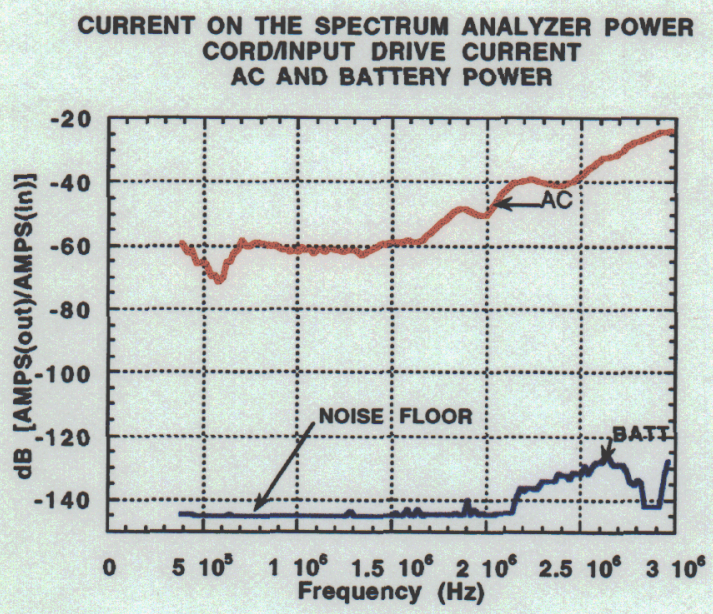

Figure 6. Unwanted current on AC power cord.

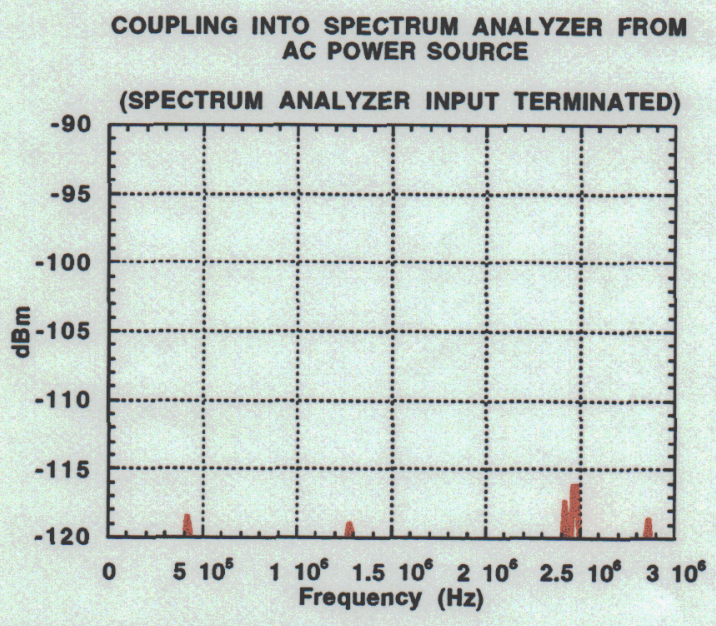

Figure 7. Direct coupling into analyzer is below noise limit.

Figure 8 shows the current transfer function of the transmitter power cord when operated from the AC line and on batteries. When operated on batteries the current is that which is generated within the transmitter and fed back through the power cord. If plugged into the AC line this would be the unwanted current fed from the transmitter internal electronics to the AC power system and will be part of the unwanted signal fed to the power ground distribution, some of which is coupled to the antenna. When operated from the AC line, the current is the vector sum of the internally generated current and the current flowing back through the power distribution system. 

CURRENT ON THE AMPLIFIER AC POWER CORDINPUT AC AND BATTERY POWER

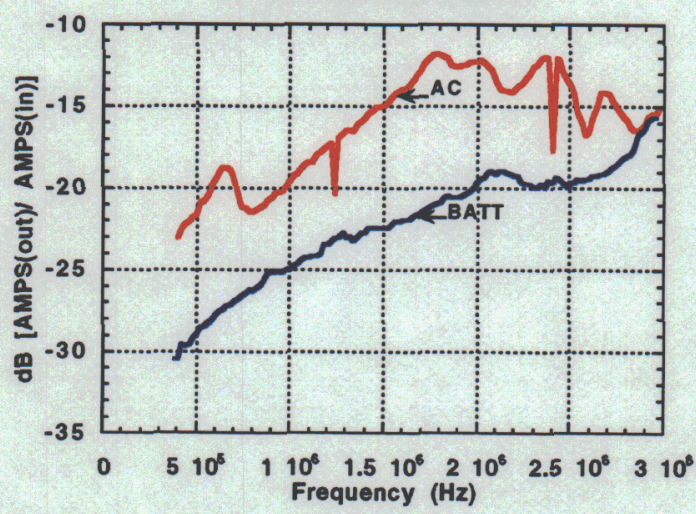

Figure 8. Current on transmitter AC power cord when operated from battery and AC.

Figure 9 describes how the current divides between the $\mathrm{AC}$ power ground and the $\mathrm{AC}$ power. Most of the unwanted current is on the ground wire.

CURRENT ON THE AC PWR GROUNDI INPUT CURRENT AND CURRENT ON THE AC PWR / INPUT CURRENT

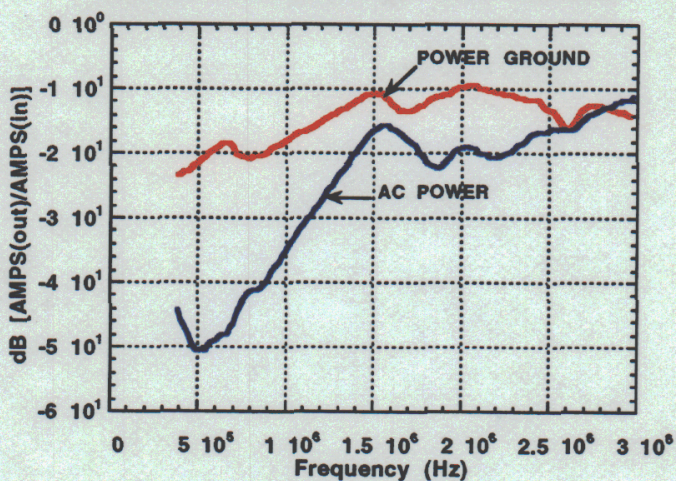

Figure 9. Current division between $\mathrm{AC}$ power ground and $\mathrm{AC}$ power.
DRIVE CURRENT VS FREQUENCY B-141 COUPLING TESTS

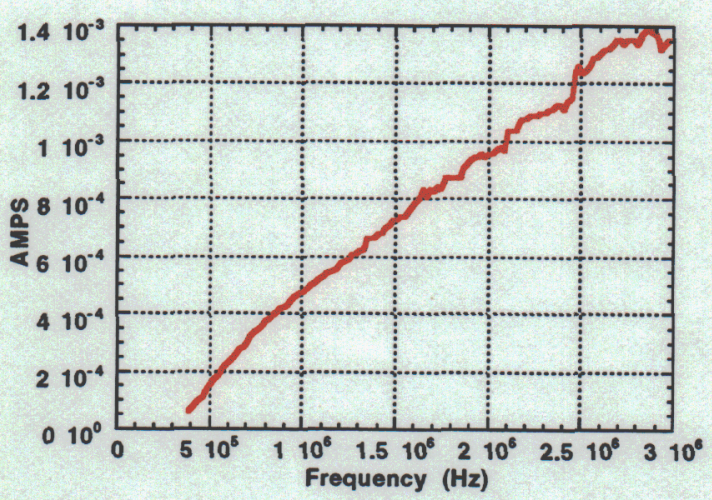

Figure 10. Input current used in transfer impedance

Figure 10 is a plot of the input current that was used in the transfer impedance $[\mathrm{Zt}=\mathrm{Eo}(\mathrm{f}) / \operatorname{lin}(\mathrm{f})]$ calculations for the rest of the analysis. Figure 11 depicts the system operation with various forms of antenna isolation. As expected, the dominant characteristic is in the unisolated case (AC + CABLE). The antenna output (transfer impedance) is considerably higher than the other cases due to the unwanted signal fed from the AC power ground to the antenna terminals. There is consistency in the other configurations if the vector addition of the antenna voltage and the unwanted voltage is taken into account. If the two signals are about the same amplitude the sum will depend on the relative phase of the signals. This could account for the apparent anomalies.

TRANSFER FUNCTIONS FOR TCOM CONNECTED WITH A CABLE OR FIBER OPTIC LINK SOURCE AND RECEIVER ON AC OR BATTERY POWER

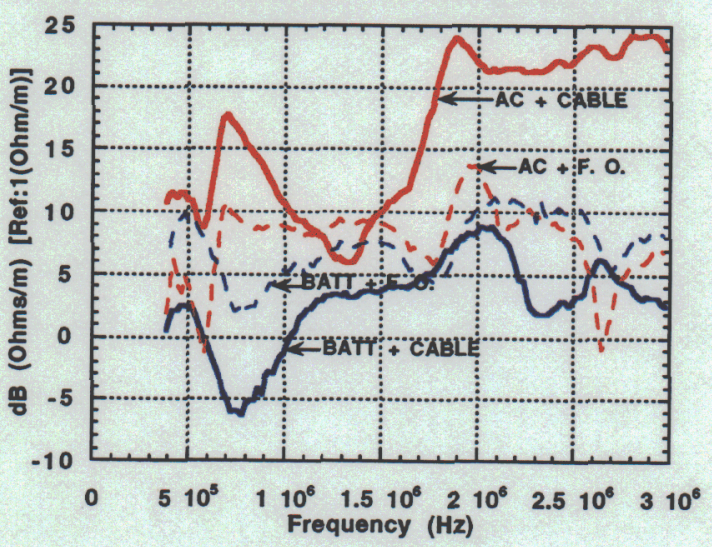

Figure 11. System operation with various forms of antenna isolation. 
In Figure 12 the antenna is always connected to the spectrum analyzer with a cable. The transfer impedance is compared for various combinations of source and receiver power. The results are consistent with high output when operated from the AC line and the unwanted signals can be coupled to the antenna.

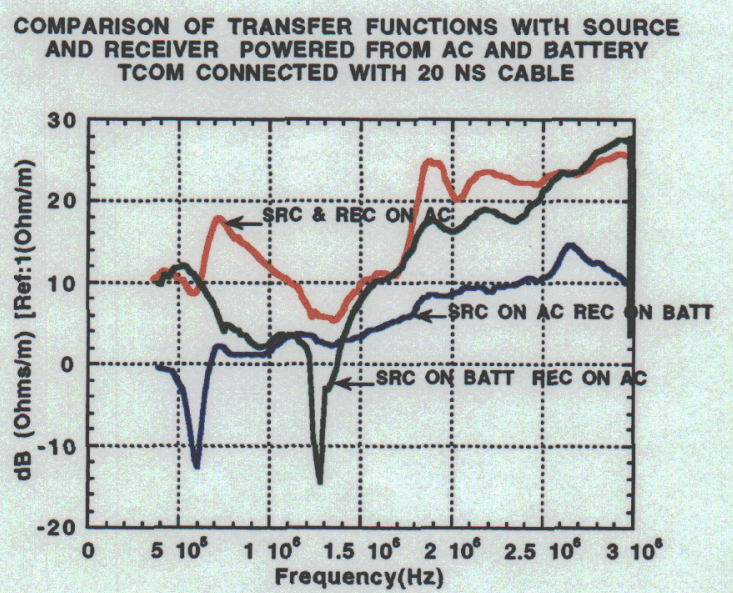

Figure 12. The antenna is always connected to the spectrum analyzer with a cable.

The punch line is Figure 13. When the antenna is completely isolated from the system with a fiberoptic link, the output is nearly independent of the power that the rest of the system uses. Certainly it doesn't matter what power the transmitter uses.

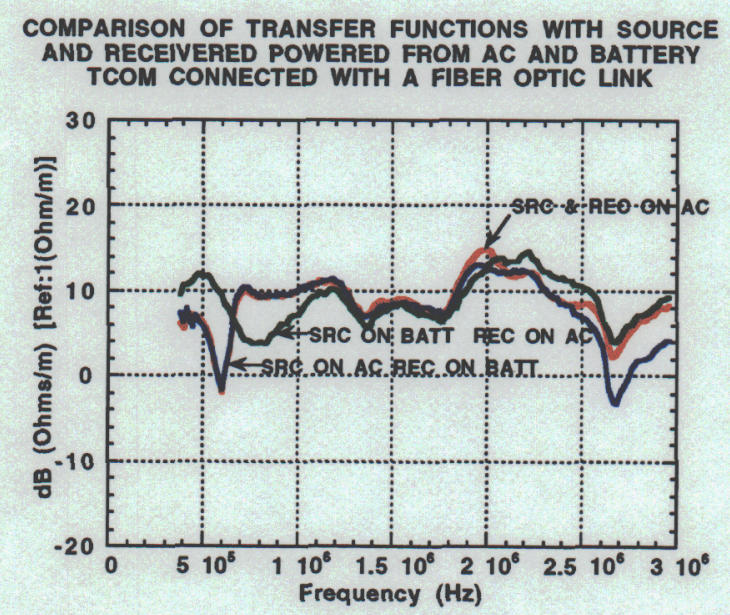

Figure 13. Antenna isolation from fiberoptic link system.

Finally the effect of putting ferrite cores on the power cord is shown in Figure 14. There is a reduction of the noise current, but that reduction would not be significant to be an effective isolation in this case.
EFFECT ON THE TRANSFER FUNCTION OF A FERRITE CORE ON THE POWER CORD (5 TURNS)

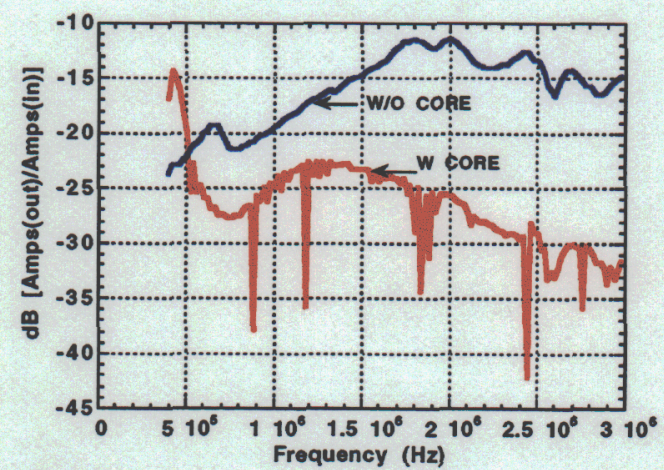

Figure 14. Effects of Ferrite core on power cord.

\section{Conclusions}

The simple noise model with the analysis shows how errors in the single ended antenna measurements can be introduced if proper attention is not given to the instrumentation grounding scheme. These errors can be removed by using a battery power supply to isolate the receiver from the $\mathrm{AC}$ power source. The best isolation can be obtained by using a fiber optic link to connect the antenna to the spectrum analyzer. Using ferrite cores on the power cords will not provide enough additional isolation, especially at the lower frequencies.

\section{Acknowledgements}

Thanks to Mike Ong for suggesting this technique to determine and quantify the various noise coupling sources, and to Jim Dunlap for his help with the instrumentation set up and data collection. 